\title{
Differences in circulating microRNA signature in Prader-Willi syndrome and non-syndromic obesity
}

\author{
Devis Pascut ${ }^{1}$, Sofia Tamini², Silvia Bresolin ${ }^{3}$, Pablo Giraudi ${ }^{1}$, Giuseppe Basso ${ }^{3}$, Alessandro Minocci ${ }^{2,4}$, \\ Claudio Tiribelli', Graziano Grugni ${ }^{2,5}$ and Alessandro Sartorio ${ }^{2,4,5}$ \\ ${ }^{1}$ Fondazione Italiana Fegato - ONLUS, Trieste, Italy \\ ${ }^{2}$ Istituto Auxologico Italiano, IRCCS, Experimental Laboratory for Auxo-endocrinological Research, Milan and Piancavallo (VB), Italy \\ ${ }^{3}$ Laboratory of Onco-Hematology, Department of Women's and Children's Health, University of Padova, Padova, Italy \\ ${ }^{4}$ Division of Metabolic Diseases, Istituto Auxologico Italiano, IRCCS, Piancavallo (VB), Italy \\ ${ }^{5}$ Division of Auxology, Istituto Auxologico Italiano, IRCCS, Piancavallo (VB), Italy \\ Correspondence should be addressed to D Pascut: devis.pascut@fegato.it
}

\begin{abstract}
Prader-Willi syndrome (PWS) represents the most common genetic-derived obesity disorder caused by the loss of expression of genes located on the paternal chromosome 15q11.2-q13. The PWS phenotype shows peculiar physical, endocrine and metabolic characteristics compared to those observed in non-syndromic essential obesity. Since miRNAs have now a well-established role in many molecular pathways, including regulatory networks related to obesity, this pilot study was aimed to characterize the expression of circulating miRNAs in PWS compared to essential obesity. The circulating miRNome of 10 PWS and 10 obese subjects, adequately matched for age, BMI and sex, was profiled throughout Genechip miRNA 4.0 microarray analysis. We identified 362 out of 2578 mature miRNAs to be expressed in serum of the studied population. The circulating miRNA signature significantly characterising the two populations include 34 differently expressed RNAs. Among them, miR-24-3p, miR-122 and miR-23a-3p highly differ between the two groups with a FC >10 in obese compared to PWS. In the obese subjects, miR-7107-5p, miR-6880-3p, miR-6793-3p and miR-4258 were associated to the presence of steatosis. A different signature of miRNAs significantly distinguished PWS with steatosis from PWS without steatosis, involving miR-619-5p, miR-4507, miR-4656, miR-7847-3p and miR-6782-5p. The miRNA target GO enrichment analysis showed the different pathway involved in these two different forms of obesity. Although the rarity of PWS actually represents a limitation to the availability of large series, the present study provides novel hints on the molecular pathogenesis of syndromic and nonsyndromic obesity.
\end{abstract}

Key Words
- microRNA
- miRNA
- Prader-Willi syndrome
- array
- obese
- non-syndromic obesity
- serum miRNA

Endocrine Connections (2018) 7, 1262-1274

\section{Introduction}

Prader-Willi syndrome (PWS) is a complex multisystem disorder due to the lack of expression of genes located on the paternal chromosome 15q11.2-q13. Together with Angelman syndrome, a totally different clinical condition,
PWS is the first example in humans of genetic imprinting (1). Three main genetic subtypes are involved namely interstitial deletion of the proximal long arm of paternal chromosome 15 (del15q11.2-q13) (DEL15, 65-75\% of https://ec.bioscientifica.com https://doi.org/10.1530/EC-18-0329 (c) 2018 The authors Published by Bioscientifica Ltd

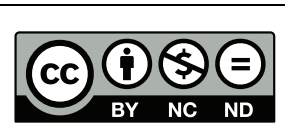

This work is licensed under a Creative Commons Attribution-NonCommercial-NoDerivatives 4.0 International License. 
cases), maternal uniparental disomy of chromosome 15 (UPD15, 20-30\% of cases) and imprinting defects (IC, $1-3 \%)(2)$.

PWS has an estimated incidence rate of 1 in 15,000 live births (3), representing the most common syndromic form of life-threatening obesity. The main characteristics of PWS include infantile hypotonia with feeding problems, early development of severe hyperphagia with food-seeking behaviour, mental retardation, behavioural problems, dysmorphic features and multiple hormonal abnormalities (4). A complex hypothalamic dysregulation is currently thought to lie at the root of PWS phenotype, including the lack of satiety, which provokes compulsive appetite resulting in extreme obesity, if uncontrolled (5). Obesity phenotype of PWS, however, shows physical, endocrine and metabolic characteristics different from those observed in simple obesity. For the same degree of weight excess (6), PWS harbours higher fat mass percentage than non-syndromic obesity, typically affecting abdomen, buttocks and thighs (4). In addition, fat free mass is significantly reduced, negatively affecting skeletal muscle performances (7). Interestingly, PWS is characterised by reduced visceral fat deposits and a predominant accumulation of subcutaneous adipose tissue, in comparison to subjects with common obesity (8). Accordingly to this peculiar body composition, individuals with PWS are characterised by lower insulin levels and higher insulin sensitivity as opposed to obese controls (9). Regardless of their metabolic advantages, however, PWS patients are at risk for developing the comorbidities conventionally related to obesity, including type 2 diabetes mellitus, metabolic syndrome, hepatobiliary complications, cardiovascular and respiratory problems. Overall, PWS subjects show a high prevalence of altered glucose metabolism that appears more common in obese and adult subjects (10), while the prevalence of metabolic syndrome is comparable to that reported in obese controls (11). Conversely, a lower risk of developing severe nonalcoholic fatty liver disease, both in children and adults, has been found in PWS $(12,13)$.

In recent years, growing evidences have identified miRNAs as important regulators of cellular pathways. They may affect lipid metabolism (14), adipocyte formation (15), metabolic activity (16) and many other pathways in obesity-related disorders. More important, the presence of circulating miRNAs has fostered intriguing studies on the role of those miRNAs as molecular biomarkers. Since miRNAs are actively released from cells into biofluids, they are considered as an important source of information for the characterisation of body diseases. miRNome profile studies may serve as tools for the identification of the molecular alterations distinctive for each pathological condition.

Based on these considerations, the primary aim of this pilot study was to characterise the expression of circulating miRNAs in a genetic-derived obesity disorder, such as PWS, compared to non-syndromic obesity.

\section{Patients}

Ten Caucasian patients with PWS (four males, six females, aged 22 to 47 years, mean \pm s.D. BMI: $37.3 \pm 6.8$ ) participated in the study (Table 1). All subjects showed the typical PWS clinical phenotype (4). Genetic analysis was performed and DEL15 was found in all patients. The patients were consecutively recruited from the Division of Auxology, Istituto Auxologico Italiano, Piancavallo (VB), Italy. Four of six PWS women had primary amenorrhoea, four females were undergoing sex steroid replacement treatment. At the time of the study, three individuals were on growth hormone treatment, whereas two had been treated in the past. Five PWS had never received growth hormone therapy.

Age, BMI, sex-matched adult patients (no.: ten, four males, six females, aged 24-44 years) suffering from essential obesity (mean \pm s.D. BMI: 42.3 \pm 5.9 ), recruited at the Division of Metabolic Diseases, Istituto Istituto Auxologico Italiano, Piancavallo (VB), Italy, were also included in the study. All females had regular menses (three were on oestrogen treatment for contraception). Apart from severe obesity, no overt endocrine disorders (diabetes mellitus, hypothyroidism, hypercortisolism, etc.) were present.

Physical examination included determination of height and weight in fasting conditions and after voiding. Standing height was determined by a wall-mounted Harpenden Stadiometer (Holtain Limited, Crymych, Dyfed, UK). Body weight was measured with subjects in minimal clothes to the nearest $0.1 \mathrm{~kg}$, using standard equipment. BMI was defined as weight in kilograms divided by the square of height in meters. Obesity was defined for any BMI over $30 \mathrm{~kg} / \mathrm{m}^{2}$.

The study was approved by the Human Research Ethics Committee of Istituto Auxologico Italiano, IRCCS, Milan, Italy (ref. no. 01C628; acronym: NAFLDmiRNAPWS). Before the study began, the purpose and objectives had been carefully explained to each patient. Written informed consent was obtained from all participants and their parents (when appropriate).

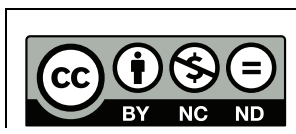

This work is licensed under a Creative Commons Attribution-NonCommercial-NoDerivatives 4.0 International License. 


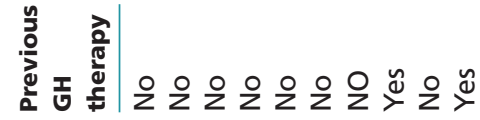

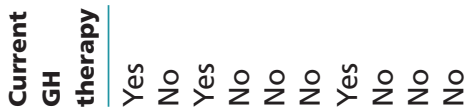

$\times \frac{2}{\times 2}$

$\frac{2}{\frac{10}{5}}$

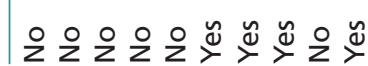

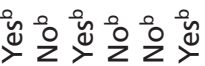

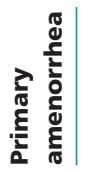

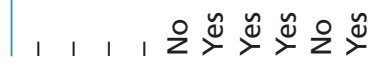

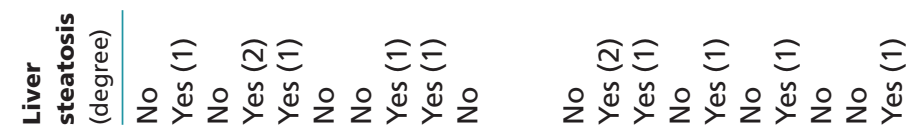

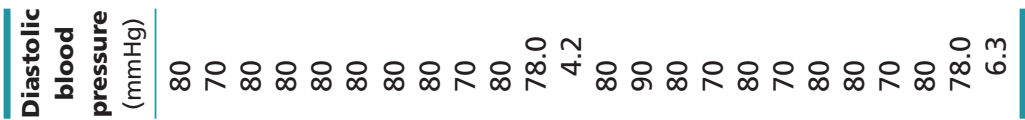

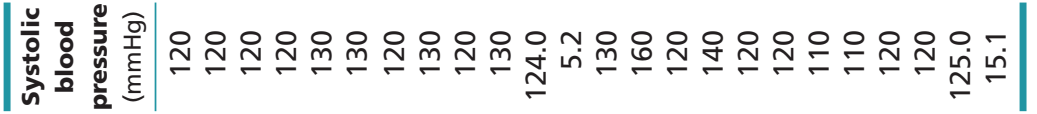

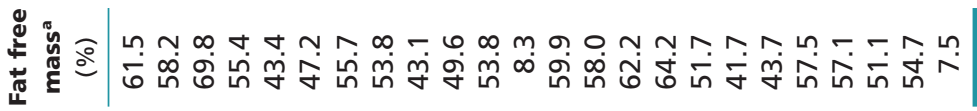

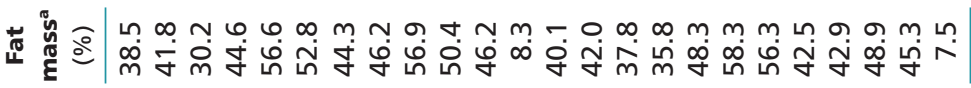

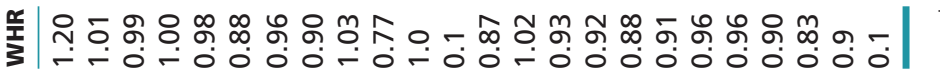
莺

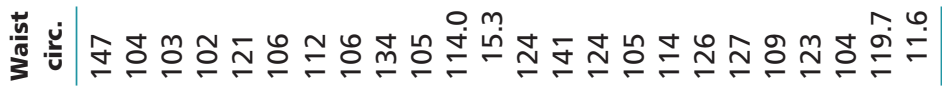

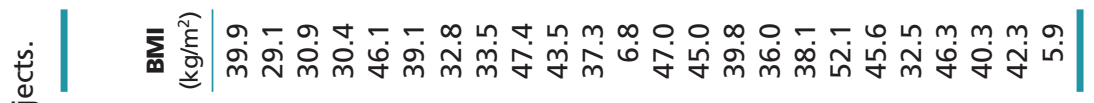
莺 产|

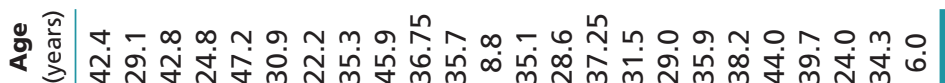

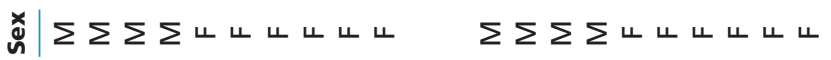

党

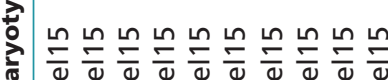

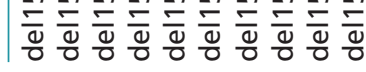

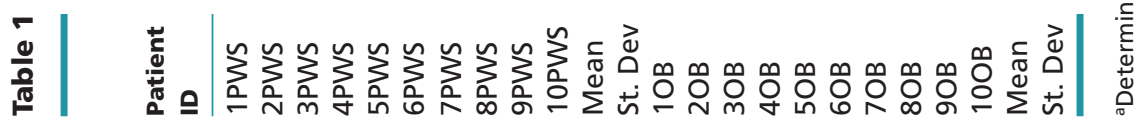




\section{Serum collection}

After an overnight fasting, blood samples for each patient were collected at $7.30 \mathrm{~h}$ by standard venipuncture in BD Vacutainer serum separating tubes (Becton Dickinson, Plymouth, UK) and were left for $1 \mathrm{~h}$ at room temperature. Afterwards, blood samples were subjected to a double centrifugation: the first step at $1900 \times \boldsymbol{g}$ at $4^{\circ} \mathrm{C}$ for $10 \mathrm{~min}$, the second one at $16000 \times \boldsymbol{g}$ at $4^{\circ} \mathrm{C}$ for $10 \mathrm{~min}$. Supernatants were transferred in new tubes and subsequently frozen at $-80^{\circ} \mathrm{C}$ for long-term storage.

\section{Assessment of haemolysis}

Serum haemoglobin was assessed with Beckman Coulter DU730 spectrophotometer using the Harboe Direct spectrophotometric method (17) with Allen correction (18): $\mathrm{Hb} \quad(\mathrm{g} / \mathrm{L})=\left(167.2 \times \mathrm{A}_{415}-83.6 \times \mathrm{A}_{380}-83.6 \times \mathrm{A}_{450}\right) \times 1 / 1000 \times$ 1 dilution in $\mathrm{dH}_{2} \mathrm{O}$. The considered cut-off for serum was $0.020 \mathrm{~g} / \mathrm{L}$.

\section{RNA extraction}

Small RNAs were isolated from $300 \mu \mathrm{L}$ of serum using the miRCURY RNA Isolation Kits - Biofluids (Exiqon, Vedbaek, Denmark). miRNAs were quantified in a Qubit 2.0 Fluorometer (Thermo Fischer Scientific) using the Qubit miRNA Assay Kit (Thermo Fischer Scientific) following the manufacturer instructions.

\section{Microarray profiling}

Serum of PWS patients and obese controls, adequately matched for age, sex and BMI, was extracted and independently profiled on the Affymetrix miRNA arrays containing 2578 Human mature miRNA probe sets. RNA was labelled with the FlashTag Biotin HSR RNA Labeling Kit (Affymetrix, Thermo Fischer Scientific) and hybridised on Genechip miRNA 4.0 (Thermo Fischer Scientific). The array cartridges were processed on an Affymetrix Fluidic Station 450 and scanned on an affymetrix GeneChip 3000 7G. The robust Multichip Analysis (RMA) algorithm was used to derive CEL file probe-level hybridization intensities at the gene expression levels.

\section{In silico data analysis}

miRNA Target prediction analysis was performed by using (DIANA)-micro T-CDS (v.5.0) prediction algorithm (19). The miRNA target pathway enrichment analysis was subsequently conducted with DIANA-miRPath (v.3.0) (20) considering either the predicted or the validated miRNA target repository in mirTarbase (21). The micro T-CDS threshold score for predicted targets was set at 0.8 and the $P$ value threshold at $P<0.05$. The enrichment analysis was performed using the Fisher's exact test with a Hypergeometric distribution corrected for multiple testing by using the false discovery rate (FDR) correction.

\section{Data analysis and statistical methods}

One-way ANOVA test was used to determine gene expression differences among groups. Multiple testing correction was performed with the Benjamini-Hochberg method and FDR, corrected $P$ values were calculated. The miRNA expression relationship among the study subgroups was analysed using Pearson correlation. Correlation matrices were generated by using Hmisc (version 4.1-1), PerformanceAnalytics (version 1.4.3541) and Corrplot (version 0.84) packages in R environment (RStudio Integrated Development for R. RStudio, Inc., Boston, MA, USA (http://www.rstudio.com/)).

\section{Results}

Serum miRNAs in PWS and non-syndromic obese subjects

We analysed the circulating miRNome of PWS vs nonsyndromic obese subjects (OB) throughout the Affymetrix Genechip miRNA 4.0 array build on miRBase release 20 (22). miRNA species were classified into five quintiles based on the 'Present'/'Absent' call of the Affymetrix algorithm (23). Undetectable miRNAs or miRNas expressed in less than five subjects were grouped together into the 1st quintile, containing 2216 out of the 2578 human mature miRNAs. The remaining quintiles ranked the miRNAs species from the rarest to the widely expressed ones.

The 2nd quintile group, including 138 miRNA species, consists of rarely detected miRNAs in both populations. Among them, miR-374a-5p, miR-4701-5p and miR-1298 were detectable only in the $\mathrm{OB}$ population, while miR-4800-5p and miR-7111-5p were present only in PWS. Mir-7111-5p was expressed in PWS with steatosis. Mir-382-5p, miR-345-5p, miR-532-5p, miR-4323-5p, mir-6796-3p and miR6836-3p were detectable mainly in the $\mathrm{OB}$ population, while the three miRNAs, miR-6721-5p, miR-2392 and miR-4486, in the PWS. The 2nd quintile miRNAs showed low average $\log 2$ signal, 
very close to the background noise, making those miRNAs preferable targets for more sensitive validation techniques to further confirm microarray results (Supplementary Table 1, see section on supplementary data given at the end of this article). The 3rd and 4th quintiles consisted respectively of 54 and 45 miRNAs (Supplementary Tables 2 and 3), group most of the regulators of lipid metabolism, adipogenesis and insulin resistance pathways. Among them, miR-23a, miR-26a, miR-150 and miR-223 were reported to be involved in adipogenesis $(24)$, insulin resistance $(25,26)$ and macrophage activation (27), while miR-130,miR-106b and miR-19b participate in cholesterol metabolism and efflux (14). The 5th quintile consisted of 125 miRNAs, including the $10 \%$ top expressed circulating miRNome with a $\log 2$ fold change (FC) greater than 5 (Supplementary Table 4). Among the highly expressed miRNA in serum, miR-92a-3p, mir-122, miR-185-5p, 191-5p were implicated in lipid metabolism and their association with obesity had already been proven (28). In particular, mir-92a-3p negatively correlated with the brown adipose tissue activity (29), while, the liver-enriched miR-122 was reported to work as central regulator of cholesterol and lipid metabolism (30) being upregulated in serum of obese young adults with insulin resistance (31) and subjects with non-alcoholic fatty liver disease (NAFLD) (32).

In the PWS and Angelman syndrome imprinted domain in chromosome 15q11-13, three miRNAs genes (miR-4509, miR-4715, miR-4508) were located. miR-4509 and miR-4715 were undetectable in both PWS and OB, while miR-4508 was expressed in both PWS and $\mathrm{OB}$ with no statistically significant differences, suggesting an alternative imprinted pattern or other coding sites within the genome.

\section{Differentially expressed miRNAs}

Thirty-four miRNAs were differently expressed between PWS and OB subjects (ANOVA $P$ value $<0.05$, FC cut-off \pm 1.5 ) (Table 2). Thirteen miRNAs were upregulated in the serum of OB vs PWS. miR-4689, miR-151a-5p and miR-106a-5p were considered as absent in the PWS population from the $\mathrm{A} / \mathrm{P}$ affymetrix algorithm, having an average signal near to the background. Three miRNAs (miR-24-3p, miR-122, miR-23a-3p) had a FC $>10$. Twenty-one miRNAs were upregulated in the serum of PWS subjects vs OB, however, with a FC $<4$. Only few differences existed between sexes, involving miR-4706, miR-193a-5p, miR-146a-5p, miR-425-5p, miR-191 and
miR23a-3p (Table 3). Interestingly miR-23a-3p had a low average $\log 2$ signal in PWS females.

When considering the presence of liver steatosis in the non-syndromic obese population, a signature of 4 miRNAs differently identified the two subgroups (OB with steatosis vs OB without steatosis): miR-7107-5p was prevalently expressed in $\mathrm{OB}$ with steatosis; on the contrary, miR-151a-5p, miR-3620-5p and miR-4433-3p were higher in the group without steatosis. It worth to be noticed that the FC between the two categories is generally low, being higher than two only for miR-151a-5p and miR-3620-5p (FC=2.39 $P=0.022$, FC=2.18 $P=0.009$, respectively) (Table 4). A different signature of miRNAs significantly distinguished PWS with steatosis from PWS without steatosis, involving miR-619-5p, miR-4507 $\quad(\mathrm{FC}=2.17 \quad P=0.018, \quad \mathrm{FC}=1.66$ $P=0.029$, respectively) which were higher in PWS without steatosis, and miR-4656, miR7847-3p and miR-6782-5p which were detectable only in the population without steatosis (Table 5).

The comparison between PWS and OB showed a large difference within the group with steatosis (Table 6). Five miRNAs were significantly higher in OB subjects. Among them mir-23a-3p showed the highest differential expression with a signal 35.67 times higher in $\mathrm{OB}$ $(P=0.028)$. Conversely, miR-1273g-3p was more abundant in PWS serum, being 4.09 time higher as compared to OB $(P=0.02)$. Other six miRNAs were moderately higher in PWS. Among them, miR-8075 showed a very high log2 signal in both groups $(6.34 \pm 0.49 ; 7.46 \pm 0.73$ in $\mathrm{OB}$ and PWS respectively).

A distinct miRNA signature of significantly different circulating miRNAs characterised the absence of liver steatosis. Twenty-six miRNAs were altered between $\mathrm{OB}$ and PWS, the great portion of miRNA results upregulated in the serum of PWS while only four miRNAs were upregulated in OB, such as miR-6068, miR-1281, miR-4530 and miR-122-5p (Table 7). The liver-specific miR-122-5p showed a strong upregulation in $\mathrm{OB}$, being 50 times higher as compared to PWS $(P=0.01)$. Indeed, the $\log 2$ average expression was $8.12 \pm 0.1 .94$ in the $\mathrm{OB}$ population compared to $2.47 \pm 2.13$ of the PWS (Table 7). Considering the miRNAs in PWS subjects, miR-3178, miR-7110-5p and miR-6891-5p, miR-1273g-3p had the highest FC compared to $\mathrm{OB}(\mathrm{FC}=5.27 P=0.02, \mathrm{FC}=4.82 P=0.031, \mathrm{FC}=3.87$ $P=0.007, \mathrm{FC}=3.32 P=0.03$, respectively). Considering the absolute expression in serum miR-3178, miR-7110-5p and miR-1273g-3p had the highest expression in PWS patients, while, miR-122-5p in OB. miR-4497, miR-7107-5p, miR-8075 and miR-5787 had a high serum expression 
Table 2 Differently expressed circulating miRNAs in obese (OB) vs Prader-Willi syndrome (PWS) subjects.

\begin{tabular}{|c|c|c|c|c|c|c|c|c|}
\hline Transcript ID & OB avg $(\log 2)$ signal & PW avg $(\log 2)$ signal & OB s.D. & PW s.D. & OB expr. & PW expr. & Fold change & P-value \\
\hline hsa-miR-3178 & 4.92 & 6.75 & 0.91 & 1.89 & $\mathrm{~T}$ & $\mathrm{~T}$ & -3.55 & 0.0408 \\
\hline hsa-miR-1273g-3p & 2.72 & 4.41 & 0.91 & 1.09 & $\mathrm{~T}$ & $\mathrm{~T}$ & -3.22 & 0.0030 \\
\hline hsa-miR-6816-5p & 2.53 & 3.94 & 0.61 & 1.29 & $\mathrm{~T}$ & $\mathrm{~T}$ & -2.66 & 0.0349 \\
\hline hsa-miR-6805-5p & 2.08 & 3.33 & 0.96 & 1.14 & $\mathrm{~T}$ & $\mathrm{~T}$ & -2.38 & 0.0176 \\
\hline hsa-miR-4497 & 5.86 & 7.01 & 1.09 & 0.7 & $\mathrm{~T}$ & $\mathrm{~T}$ & -2.22 & 0.0064 \\
\hline hsa-miR-619-5p & 2.34 & 3.49 & 0.48 & 1.09 & $\mathrm{~T}$ & $\mathrm{~T}$ & -2.21 & 0.0048 \\
\hline hsa-miR-320e & 1.66 & 2.71 & 0.73 & 0.93 & $\mathrm{~T}$ & $\mathrm{~T}$ & -2.07 & 0.0100 \\
\hline hsa-miR-7150 & 1.6 & 2.65 & 0.8 & 0.81 & $\mathrm{~T}$ & $\mathrm{~T}$ & -2.07 & 0.0216 \\
\hline hsa-miR-4706 & 2.06 & 3.1 & 0.45 & 1.1 & $\mathrm{~T}$ & $\mathrm{~T}$ & -2.05 & 0.0005 \\
\hline hsa-miR-4429 & 2.97 & 3.97 & 0.84 & 0.98 & $\mathrm{~T}$ & $\mathrm{~T}$ & -1.99 & 0.0075 \\
\hline hsa-miR-6891-5p & 1.85 & 2.84 & 0.92 & 0.73 & $\mathrm{~T}$ & $\mathrm{~T}$ & -1.99 & 0.0302 \\
\hline hsa-miR-8075 & 5.88 & 6.8 & 0.58 & 0.59 & $\mathrm{~T}$ & $\mathrm{~T}$ & -1.9 & 0.0010 \\
\hline hsa-miR-1268a & 1.33 & 2.24 & 0.46 & 0.95 & $\mathrm{~T}$ & $\mathrm{~T}$ & -1.87 & 0.0113 \\
\hline hsa-miR-6749-5p & 2.1 & 2.9 & 0.53 & 0.59 & $\mathrm{~T}$ & $\mathrm{~T}$ & -1.74 & 0.0099 \\
\hline hsa-miR-6722-3p & 1.88 & 2.67 & 0.61 & 0.93 & $\mathrm{~T}$ & $\mathrm{~T}$ & -1.73 & 0.0216 \\
\hline hsa-miR-6085 & 2.65 & 3.44 & 0.56 & 0.83 & $\mathrm{~T}$ & $\mathrm{~T}$ & -1.72 & 0.0027 \\
\hline hsa-miR-6794-5p & 2.83 & 3.59 & 0.55 & 0.72 & $\mathrm{~T}$ & $\mathrm{~T}$ & -1.68 & 0.0217 \\
\hline hsa-miR-5787 & 6.05 & 6.79 & 0.31 & 0.46 & $\mathrm{~T}$ & $\mathrm{~T}$ & -1.67 & 4.19E-06 \\
\hline hsa-miR-1275 & 1.54 & 2.28 & 0.51 & 0.51 & $\mathrm{~T}$ & $\mathrm{~T}$ & -1.67 & 0.0066 \\
\hline hsa-miR-6779-5p & 1.34 & 2.04 & 0.52 & 0.6 & $\mathrm{~T}$ & $\mathrm{~T}$ & -1.62 & 0.0192 \\
\hline hsa-miR-4632-5p & 1.3 & 1.93 & 0.5 & 0.57 & $\mathrm{~F}$ & $\mathrm{~T}$ & -1.54 & 0.0231 \\
\hline hsa-miR-4689 & 2.1 & 1.29 & 0.74 & 0.64 & $\mathrm{~T}$ & $\mathrm{~F}$ & 1.76 & 0.0271 \\
\hline hsa-miR-1281 & 3.27 & 2.26 & 0.62 & 0.85 & $\mathrm{~T}$ & $\mathrm{~T}$ & 2.01 & 0.0027 \\
\hline hsa-miR-151a-5p & 2.44 & 1.04 & 1.41 & 1.01 & $\mathrm{~T}$ & $\mathrm{~F}$ & 2.63 & 0.0104 \\
\hline hsa-miR-4530 & 3.37 & 1.74 & 0.98 & 0.64 & $\mathrm{~T}$ & $\mathrm{~T}$ & 3.11 & 0.0022 \\
\hline hsa-miR-106a-5p & 3.75 & 1.18 & 1.96 & 1.76 & $\mathrm{~T}$ & $\mathrm{~F}$ & 5.95 & 0.0330 \\
\hline hsa-miR-191-5p & 6.08 & 3.48 & 2.09 & 1.81 & $\mathrm{~T}$ & $\mathrm{~T}$ & 6.1 & 0.0435 \\
\hline hsa-miR-425-5p & 3.83 & 1.21 & 1.47 & 1.62 & $\mathrm{~T}$ & $\mathrm{~T}$ & 6.14 & 0.0301 \\
\hline hsa-miR-106b-5p & 3.89 & 1.21 & 1.74 & 1.45 & $\mathrm{~T}$ & $\mathrm{~T}$ & 6.38 & 0.0136 \\
\hline hsa-miR-92a-3p & 6.65 & 3.97 & 2.39 & 2.11 & $\mathrm{~T}$ & $\mathrm{~T}$ & 6.42 & 0.0486 \\
\hline hsa-miR-93-5p & 4.53 & 1.47 & 2.37 & 1.95 & $\mathrm{~T}$ & $\mathrm{~T}$ & 8.35 & 0.0361 \\
\hline hsa-miR-24-3p & 5.09 & 1.35 & 3 & 2.12 & $\mathrm{~T}$ & $\mathrm{~T}$ & 13.32 & 0.0238 \\
\hline hsa-miR-122-5p & 6.92 & 2.84 & 2.39 & 1.97 & $\mathrm{~T}$ & $\mathrm{~T}$ & 17 & 0.0078 \\
\hline hsa-miR-23a-3p & 6.16 & 2.05 & 2.59 & 2.33 & $\mathrm{~T}$ & $\mathrm{~T}$ & 17.25 & 0.0239 \\
\hline
\end{tabular}

in both populations (Table 7). miR-151a-5p resulted expressed in OB only, with a $\log 2$ signal of $2.95 \pm 1.52$.

\section{In silico circulating miRNA target prediction and pathways enrichment analysis}

The differently upregulated miRNA between OB and PWS were further considered for an in silico miRNA target identification and GO enrichment analysis.

To identify the significantly enriched GO pathways a miRPath v 3.0 (20) (DIANA tool) analysis was performed.
The experimentally validated miRNA targets of the upregulated miRNA signature in $\mathrm{OB}$ were searched in mirTarBase v.7.0 integrated in DIANA miRPath $\mathrm{v}$ 3.0. Among the 13 selected miRNAs, only two (miR-4530 and miR-4689) had no experimentally validated target identified yet (Supplementary File 1). Initially the enrichment analysis for each miRNA was performed and a $P$ value for every pathway was calculated. Merged $P$ values were then calculated combining the previously significance levels using Fisher's meta-analysis method, resulting in the probability that a determinate pathway

Table 3 Differently expressed circulating miRNAs between sexes in the two considered populations.

\begin{tabular}{|c|c|c|}
\hline Transcript ID & F avg $(\log 2)$ signal & M avg $(\log 2)$ signal \\
\hline hsa-miR-23a-3p & 1.62 & 5.69 \\
\hline hsa-miR-191-5p & 3.46 & 5.61 \\
\hline hsa-miR-425-5p & 2.04 & 3.94 \\
\hline hsa-miR-146a-5p & 1.95 & 3.28 \\
\hline hsa-miR-193a-5p & 2.66 & 3.51 \\
\hline hsa-miR-4706 & 2.56 & 1.97 \\
\hline
\end{tabular}

\begin{tabular}{lll} 
F s.D. & & M s.D. \\
\hline 2.83 & & 1.95 \\
2.24 & & 1.1 \\
1.68 & & 1.46 \\
1.13 & & 1.35 \\
0.98 & & 0.8 \\
1.22 & & 0.56 \\
\hline
\end{tabular}

\begin{tabular}{c} 
F expr. \\
\hline $\mathrm{T}$ \\
$\mathrm{T}$ \\
$\mathrm{T}$ \\
$\mathrm{T}$ \\
$\mathrm{T}$ \\
$\mathrm{T}$ \\
\hline
\end{tabular}

\begin{tabular}{c} 
M expr. \\
\hline $\mathrm{T}$ \\
$\mathrm{T}$ \\
$\mathrm{T}$ \\
$\mathrm{T}$ \\
$\mathrm{T}$ \\
$\mathrm{T}$
\end{tabular}

\begin{tabular}{c} 
Fold change \\
\hline-16.82 \\
-4.42 \\
-3.73 \\
-2.51 \\
-1.8 \\
1.51
\end{tabular}

\begin{tabular}{c}
$P$-value \\
\hline 0.0237 \\
0.0109 \\
0.0314 \\
0.0448 \\
0.0340 \\
0.0273
\end{tabular}


Table 4 Differently expressed circulating miRNAs in obese with steatosis (OBS-) vs Obese without steatosis (OBS+).

\begin{tabular}{|c|c|c|}
\hline Transcript ID & OBS+ avg $(\log 2)$ signal & OBS- avg $(\log 2)$ signal \\
\hline hsa-miR-151a-5p & 1.69 & 2.95 \\
\hline hsa-miR-23a-5p & 0.85 & 2 \\
\hline hsa-miR-3620-5p & 2.66 & 3.79 \\
\hline hsa-miR-576-5p & 0.36 & 0.97 \\
\hline hsa-miR-4433-3p & 1.44 & 2.03 \\
\hline hsa-miR-4258 & 1.8 & 1.2 \\
\hline hsa-miR-6793-3p & 2 & 1.37 \\
\hline hsa-miR-6750-3p & 1.42 & 0.78 \\
\hline hsa-miR-6880-3p & 1.52 & 0.82 \\
\hline hsa-miR-7107-5p & 6.46 & 5.59 \\
\hline
\end{tabular}

\begin{tabular}{c}
\hline OBS+ S.D. \\
\hline 1.28 \\
0.36 \\
0.81 \\
0.41 \\
0.37 \\
0.32 \\
0.58 \\
0.35 \\
0.47 \\
1.04 \\
\hline
\end{tabular}

\begin{tabular}{c}
\hline OBS- S.D. \\
\hline 1.52 \\
0.68 \\
0.28 \\
0.15 \\
0.56 \\
0.36 \\
0.46 \\
0.13 \\
0.32 \\
1.7 \\
\hline
\end{tabular}

\begin{tabular}{c} 
OBS+ expr. \\
\hline$T$ \\
$F$ \\
$T$ \\
$F$ \\
$T$ \\
$T$ \\
$T$ \\
$F$ \\
$T$ \\
$T$ \\
\hline
\end{tabular}

\begin{tabular}{c} 
OBS- expr. \\
\hline$T$ \\
$T$ \\
$T$ \\
$F$ \\
$T$ \\
$F$ \\
$F$ \\
$F$ \\
$F$ \\
$T$ \\
\hline
\end{tabular}

\begin{tabular}{|c|c|}
\hline Fold change & $P$-value \\
\hline-2.39 & 0.0225 \\
\hline-2.21 & 0.0100 \\
\hline-2.18 & 0.0093 \\
\hline-1.52 & 0.0254 \\
\hline-1.5 & 0.0252 \\
\hline 1.52 & 0.0011 \\
\hline 1.55 & 0.0212 \\
\hline 1.56 & 0.0440 \\
\hline 1.63 & 0.0163 \\
\hline 1.83 & 0.0268 \\
\hline
\end{tabular}

is targeted by at least one miRNA out of the circulating signature in OB. We generated a Heatmap with the first 45 enriched GO biological processed pathways. Most of the highly enriched pathways consisted of general cellular metabolic processes (Fig. 1).

miR-24-3p, miR-92a-3p and miR-93-5p were highly associated to 'cellular lipid metabolic process' pathway. In addition, mir-93-5p targets were also enriched in the 'FGF receptor-signalling' pathway and 'insulin receptorsignalling' pathway (Fig. 1).

Since among the 21 miRNAs upregulated in PWS subjects, only five miRNAs (miR-320e, miR-1275, miR-1263g-3p, miR-4429 and miR-4632-5p) had experimentally validated targets (Supplementary File 2 ), we performed the miRPath analysis by using the identified by using the DIANA-microT-CDS tool (19) that combines miR-target predictions based on both CDS and the 3'-untranslated regions (3'-UTRs) of the RNA target (Supplementary File 2). Despite the prediction, the enrichment was performed unsatisfactory with only ten pathways involved (Fig. 2). Only few miRNAs had a significant role in the predicted pathways related to general biological processes. However, it is noteworthy the enrichment of the 'neurotrophin TRK receptor signalling' pathway since the brain-neurotrophic factor (BDNF) haploinsufficiency is associated to PWS.

\section{Discussion}

PWS is the most common genetic-derived obesity disorder, determined by the absent expression of paternal alleles in the PWS critical region on chromosome 15. Within the imprinted region, 14 known genes are located, generating protein-coding transcripts, long noncoding RNAs (lncRNAs), small nucleolar RNAs (snoRNAs), PIWI-interacting RNAS (piRNAs) and miRNAs (33). The well-defined genetic determinants, leading to this obesity-related disorder, could contribute in elucidating the molecular pathways involved in other obesity-related diseases as well. As fundamental post-transcriptional gene regulators, miRNAs have now a well-established role in cell molecular pathways, including regulatory gene networks related to obesity $(34,35)$. Recently, Thomou and coll. (36) have identified the adipose tissue as an important source of circulating exosomal miRNAs, working as endocrine regulators of gene expression in distant tissues. In their experiments, the adipose tissue-derived exosomal miRNAs were able to influence the expression of liver FGF21 in a mouse model. Thus, circulating miRNAs can be considered not only as potential biomarkers of the disease but, also, as an informative tool mirroring the cell mechanisms and pathways involved in obesity-related diseases.

Table 5 Differently expressed circulating miRNAs between Prader-Willi syndrome subjects with (PWS+) and without steatosis (PWS-).

\begin{tabular}{|c|c|c|c|c|c|c|c|c|}
\hline $\begin{array}{l}\text { Transcript ID } \\
\text { (array design) }\end{array}$ & PWS+ avg $(\log 2)$ signal & PWS- avg $(\log 2)$ signal & PWS+ S.D. & PWS- S.D. & PWS+ expr. & PWS- expr. & Fold change & P-value \\
\hline hsa-miR-619-5p & 2.61 & 3.73 & 1.29 & 0.49 & $\mathrm{~T}$ & $\mathrm{~T}$ & -2.17 & 0.0189 \\
\hline hsa-miR-4656 & 1.01 & 1.85 & 0.29 & 0.23 & $\mathrm{~F}$ & $\mathrm{~T}$ & -1.79 & 0.0001 \\
\hline hsa-miR-7847-3p & 0.9 & 1.7 & 0.17 & 0.5 & $\mathrm{~F}$ & $\mathrm{~T}$ & -1.74 & 0.0005 \\
\hline hsa-miR-4507 & 1.82 & 2.55 & 0.48 & 0.71 & $\mathrm{~T}$ & $\mathrm{~T}$ & -1.66 & 0.0294 \\
\hline hsa-miR-6782-5p & 1.36 & 2 & 0.46 & 0.8 & $\mathrm{~F}$ & $\mathrm{~T}$ & -1.56 & 0.0145 \\
\hline hsa-miR-6729-3p & 1.54 & 0.86 & 0.36 & 0.2 & $\mathrm{~F}$ & $\mathrm{~F}$ & 1.61 & 0.0044 \\
\hline $\begin{array}{l}\text { https://ec.bioscientifica } \\
\text { https://doi.org/10.1530 }\end{array}$ & $\begin{array}{l}\text { com } \\
\text { /EC-18-0329 }\end{array}$ & $\begin{array}{r}\text { (c) } 2018 \text { The authors } \\
\text { Published by Bioscientifica Ltd }\end{array}$ & & & $\begin{array}{l}\text { This w } \\
\text { Attrib } \\
\text { Intern }\end{array}$ & $\begin{array}{l}\text { rk is licensed unc } \\
\text { ion-NonCommer } \\
\text { ional License. }\end{array}$ & $\begin{array}{l}\text { er a Creative Comr } \\
\text { cial-NoDerivatives }\end{array}$ & $\begin{array}{l}\text { nons } \\
4.0\end{array}$ \\
\hline
\end{tabular}


Table 6 Differently expressed circulating miRNAs between Prader-Willi syndrome subjects (PWS+) and obese with steatosis (OBS+).

\begin{tabular}{llll} 
Transcript ID & OBS+ avg $(\log 2)$ signal & PWS+ avg (log2) signal \\
\cline { 1 - 1 } hsa-miR-1273g-3p & 2.26 & 4.29 \\
hsa-miR-8075 & 6.34 & 7.46 \\
hsa-miR-4429 & 2.59 & 3.69 \\
hsa-miR-1275 & 1.4 & 2.42 \\
hsa-miR-6805-5p & 1.68 & 2.67 \\
hsa-miR-6749-5p & 2 & 2.96 \\
hsa-miR-4706 & 2.04 & 2.88 \\
hsa-miR-4530 & 3.39 & 1.57 \\
hsa-miR-425-5p & 3.92 & 1.09 \\
hsa-miR-106b-5p & 4.28 & 1.27 \\
hsa-miR-191-5p & 6.31 & 3.08 \\
hsa-miR-23a-3p & 6.64 & 1.48 \\
\hline
\end{tabular}

\begin{tabular}{|c|c|}
\hline OBS+ S.D. & PWS+ S.D. \\
\hline 0.76 & 1.35 \\
\hline 0.49 & 0.73 \\
\hline 0.82 & 1.02 \\
\hline 0.53 & 0.52 \\
\hline 0.89 & 1.5 \\
\hline 0.47 & 0.8 \\
\hline 0.45 & 0.74 \\
\hline 1.16 & 0.73 \\
\hline 1.71 & 1.15 \\
\hline 1.68 & 0.45 \\
\hline 2.42 & 1.3 \\
\hline 2.86 & 1.74 \\
\hline
\end{tabular}

\begin{tabular}{c}
\hline OBS+ expr \\
\hline$T$ \\
$T$ \\
$T$ \\
$T$ \\
$T$ \\
$T$ \\
$T$ \\
$T$ \\
$T$ \\
$T$ \\
$T$ \\
$T$ \\
\hline
\end{tabular}

\begin{tabular}{|c|c|c|}
\hline PWS+ expr. & Fold change & $P$-value \\
\hline $\mathrm{T}$ & -4.09 & 0.0208 \\
\hline $\mathrm{T}$ & -2.18 & 0.0173 \\
\hline $\mathrm{T}$ & -2.15 & 0.0381 \\
\hline $\mathrm{T}$ & -2.03 & 0.0361 \\
\hline $\mathrm{T}$ & -1.99 & 0.0325 \\
\hline $\mathrm{T}$ & -1.94 & 0.0278 \\
\hline $\mathrm{T}$ & -1.79 & 0.0298 \\
\hline $\mathrm{T}$ & 3.52 & 0.0382 \\
\hline $\mathrm{T}$ & 7.09 & 0.0371 \\
\hline $\mathrm{T}$ & 8.03 & 0.0202 \\
\hline $\mathrm{T}$ & 9.38 & 0.0487 \\
\hline $\mathrm{T}$ & 35.67 & 0.0280 \\
\hline
\end{tabular}

In our work, we analysed the circulating miRNome in a cohort of patients suffering from a genetic-related obesity disease, such as PWS, compared to an age-, BMI, sex-matched cohort of patients with essential obesity. To our knowledge, this is the first description of a comprehensive circulating miRNA profile comparing the two obese populations.

Only a small portion of the mature miRNA sequences in miRBase v.20 were detectable in the analysed serum samples $(n=362)$. Among the 13 up-regulated serum
miRNA in OB, miR-24-3p and miR-122 had the highest expression. These miRNAs, together with mir-23a-3p, have been already extensively studied in obesity-related diseases for their role as regulators of lipid metabolism in liver $(37,38)$. In line with our observations, Nunez Lopes and coll. (39) found that increased plasma circulating levels of miR-24 were associated with obesity and diabetes spectrum. Similarly, Wang and coll. (31) correlated the elevated circulating levels of miR-122 with the obesity degree.

Table 7 Differently expressed circulating miRNAs between Prader-Willi syndrome subjects (PWS-) and obese without steatosis (OBS-).

\begin{tabular}{|c|c|c|}
\hline Transcript ID & $\begin{array}{c}\text { OBS- avg }(\log 2) \\
\text { signal }\end{array}$ & $\begin{array}{c}\text { PWS- avg }(\log 2) \\
\text { signal }\end{array}$ \\
\hline hsa-miR-3178 & 4.2 & 6.6 \\
\hline hsa-miR-7110-5p & 3.97 & 6.24 \\
\hline hsa-miR-6891-5p & 1.36 & 3.31 \\
\hline hsa-miR-1273g-3p & 3.3 & 5.03 \\
\hline hsa-miR-1268a & 1.19 & 2.72 \\
\hline hsa-miR-4706 & 1.91 & 3.42 \\
\hline hsa-miR-4497 & 5.7 & 7.2 \\
\hline hsa-miR-619-5p & 2.25 & 3.73 \\
\hline hsa-miR-7107-5p & 5.59 & 6.79 \\
\hline hsa-miR-6798-5p & 2.13 & 3.31 \\
\hline hsa-miR-8075 & 5.72 & 6.79 \\
\hline hsa-miR-7150 & 1.27 & 2.27 \\
\hline hsa-miR-6769b-5p & 1.97 & 2.88 \\
\hline hsa-miR-6085 & 2.53 & 3.39 \\
\hline hsa-miR-5787 & 5.94 & 6.76 \\
\hline hsa-miR-6722-3p & 2.1 & 2.91 \\
\hline hsa-miR-320e & 1.93 & 2.73 \\
\hline hsa-miR-4507 & 1.85 & 2.55 \\
\hline hsa-mir-550a-1 & 1.92 & 2.57 \\
\hline hsa-mir-550a-2 & 1.92 & 2.57 \\
\hline hsa-mir-550a-3 & 1.92 & 2.57 \\
\hline hsa-miR-6068 & 3.59 & 2.78 \\
\hline hsa-miR-1281 & 3.18 & 1.8 \\
\hline hsa-miR-4530 & 3.33 & 1.79 \\
\hline hsa-miR-151a-5p & 2.95 & 0.68 \\
\hline hsa-miR-122-5p & 8.12 & 2.47 \\
\hline
\end{tabular}

\begin{tabular}{|c|c|}
\hline OBS- S.D. & PWS- S.D. \\
\hline 1.08 & 0.71 \\
\hline 1.22 & 0.99 \\
\hline 0.79 & 0.77 \\
\hline 1.04 & 0.79 \\
\hline 0.65 & 0.87 \\
\hline 0.48 & 1.41 \\
\hline 1.14 & 0.53 \\
\hline 0.34 & 0.49 \\
\hline 1.7 & 0.76 \\
\hline 0.65 & 0.88 \\
\hline 0.68 & 0.44 \\
\hline 0.44 & 0.62 \\
\hline 0.43 & 0.44 \\
\hline 0.63 & 0.6 \\
\hline 0.37 & 0.64 \\
\hline 0.84 & 0.84 \\
\hline 0.96 & 1 \\
\hline 0.67 & 0.71 \\
\hline 0.3 & 0.42 \\
\hline 0.3 & 0.42 \\
\hline 0.3 & 0.42 \\
\hline 0.93 & 1.01 \\
\hline 0.77 & 0.69 \\
\hline 0.84 & 0.62 \\
\hline 1.52 & 1.41 \\
\hline 1.94 & 2.13 \\
\hline
\end{tabular}

\begin{tabular}{c}
\hline OBS- expr. \\
\hline $\mathrm{T}$ \\
$\mathrm{T}$ \\
$\mathrm{T}$ \\
$\mathrm{T}$ \\
$\mathrm{T}$ \\
$\mathrm{T}$ \\
$\mathrm{T}$ \\
$\mathrm{T}$ \\
$\mathrm{T}$ \\
$\mathrm{T}$ \\
$\mathrm{T}$ \\
$\mathrm{T}$ \\
$\mathrm{T}$ \\
$\mathrm{T}$ \\
$\mathrm{T}$ \\
$\mathrm{T}$ \\
$\mathrm{T}$ \\
$\mathrm{T}$ \\
$\mathrm{T}$ \\
$\mathrm{T}$ \\
$\mathrm{T}$ \\
$\mathrm{T}$ \\
$\mathrm{T}$ \\
$\mathrm{T}$ \\
$\mathrm{T}$ \\
$\mathrm{T}$ \\
\end{tabular}

\begin{tabular}{|c|c|c|}
\hline PWS- expr. & Fold change & P-value \\
\hline $\mathrm{T}$ & -5.27 & 0.0254 \\
\hline $\mathrm{T}$ & -4.82 & 0.0311 \\
\hline $\mathrm{T}$ & -3.87 & 0.0072 \\
\hline $\mathrm{T}$ & -3.32 & 0.0323 \\
\hline $\mathrm{T}$ & -2.89 & 0.0144 \\
\hline $\mathrm{T}$ & -2.87 & 0.0018 \\
\hline $\mathrm{T}$ & -2.83 & 0.0191 \\
\hline $\mathrm{T}$ & -2.79 & 0.0011 \\
\hline $\mathrm{T}$ & -2.3 & 0.0477 \\
\hline $\mathrm{T}$ & -2.26 & 0.0187 \\
\hline $\mathrm{T}$ & -2.09 & 0.0095 \\
\hline $\mathrm{T}$ & -2 & 0.0075 \\
\hline $\mathrm{T}$ & -1.88 & 0.0081 \\
\hline $\mathrm{T}$ & -1.81 & 0.0018 \\
\hline $\mathrm{T}$ & -1.77 & 0.0001 \\
\hline $\mathrm{T}$ & -1.75 & 0.0498 \\
\hline $\mathrm{T}$ & -1.74 & 0.0408 \\
\hline $\mathrm{T}$ & -1.63 & 0.0393 \\
\hline $\mathrm{T}$ & -1.58 & 0.0321 \\
\hline $\mathrm{T}$ & -1.58 & 0.0321 \\
\hline $\mathrm{T}$ & -1.58 & 0.0321 \\
\hline $\mathrm{T}$ & 1.76 & 0.0203 \\
\hline $\mathrm{T}$ & 2.59 & 0.0061 \\
\hline $\mathrm{T}$ & 2.9 & 0.0112 \\
\hline $\mathrm{F}$ & 4.84 & 0.0200 \\
\hline $\mathrm{T}$ & 50.02 & 0.0106 \\
\hline
\end{tabular}



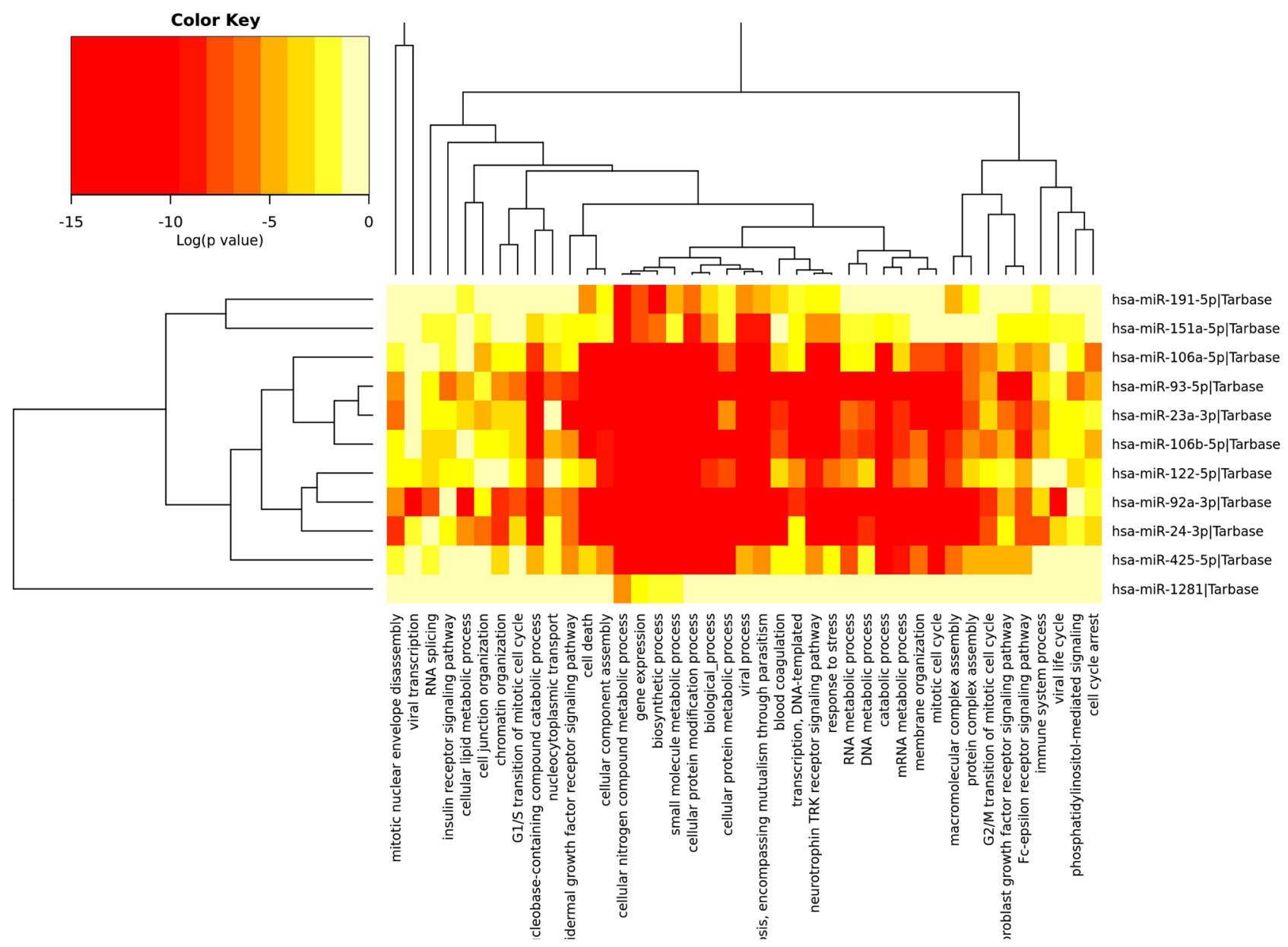

Figure 1

Heatmap of the top 45 enriched pathways related to the validated mRNA targets of the up-regulated miRNA in OB. The colour scale encodes the amount of $P$-value in logarithmic scale. The enrichment analysis was performed by using the Fisher's exact test with a hypergeometric distribution corrected for multiple testing by using the False Discovery Rate (FDR) correction.

Interestingly, the OB upregulated miR-93-5p, miR-106a-5p, miR-106b-5p and the nearly significant miR-17-5p $(P<0.058)$ belong to the miR-17/17-5p/ 20ab/20b-5p/93/106ab/427/518a-3p/519d family. Their expression is 6 to 8 folds higher in OB with a high degree of correlation among each other (Supplementary Fig. 1). In addition, they cluster together in the ontological analysis (Fig. 1), enforcing their synergism in the pathway regulation in OB. Conversely, the low expression and a poor Pearson correlation in PWS, suggested a different role of those miRNAs in this disease (Supplementary Fig. 1). miR-17-5p and miR-106a have been identified as important regulators of adipocyte differentiation, negatively regulating $B M P 2$, a modulator in $M S X 2 / T A Z$ and PPAR p pathway involved in the switch between adipocyte and osteoblast differentiation (40). In addition miR-106b and miR-93 are reported to be negative

https.//ec.bioscientifica.com

https://doi.org/10.1530/EC-18-0329

(c) 2018 The authors Published by Bioscientifica Ltd regulators of brown adipocyte differentiation in mice (41). The suppression of miR-93 is associated with an increase of white adipose tissue related to an increase of adipocyte precursors through the pluripotency-associated transcription factor $\mathrm{Tbx} 3$ and to an increase of the adipogenesis through Sirt7 (42). Moreover, the absence of miR-106b and miR-93 lead to an upregulation of Fabp4, PPAR $\gamma$ and adiponectin (41), thus suggesting a possible role of this miRNA family as general regulators of adipogenesis. The increased adiponectin levels observed by $\mathrm{Wu}$ and colleagues (41) after mir-106b-93 knockdown in mice, and the low expression detected in our PWS cohort, are in line with the higher adiponectin levels measured in PWS compared with non-syndromic obese in previous studies (43). Unfortunately, we were not able to correlate the adiponectin levels to mir-93 miR-106b expression in our patients. The low expression levels of miR-17-5p, 

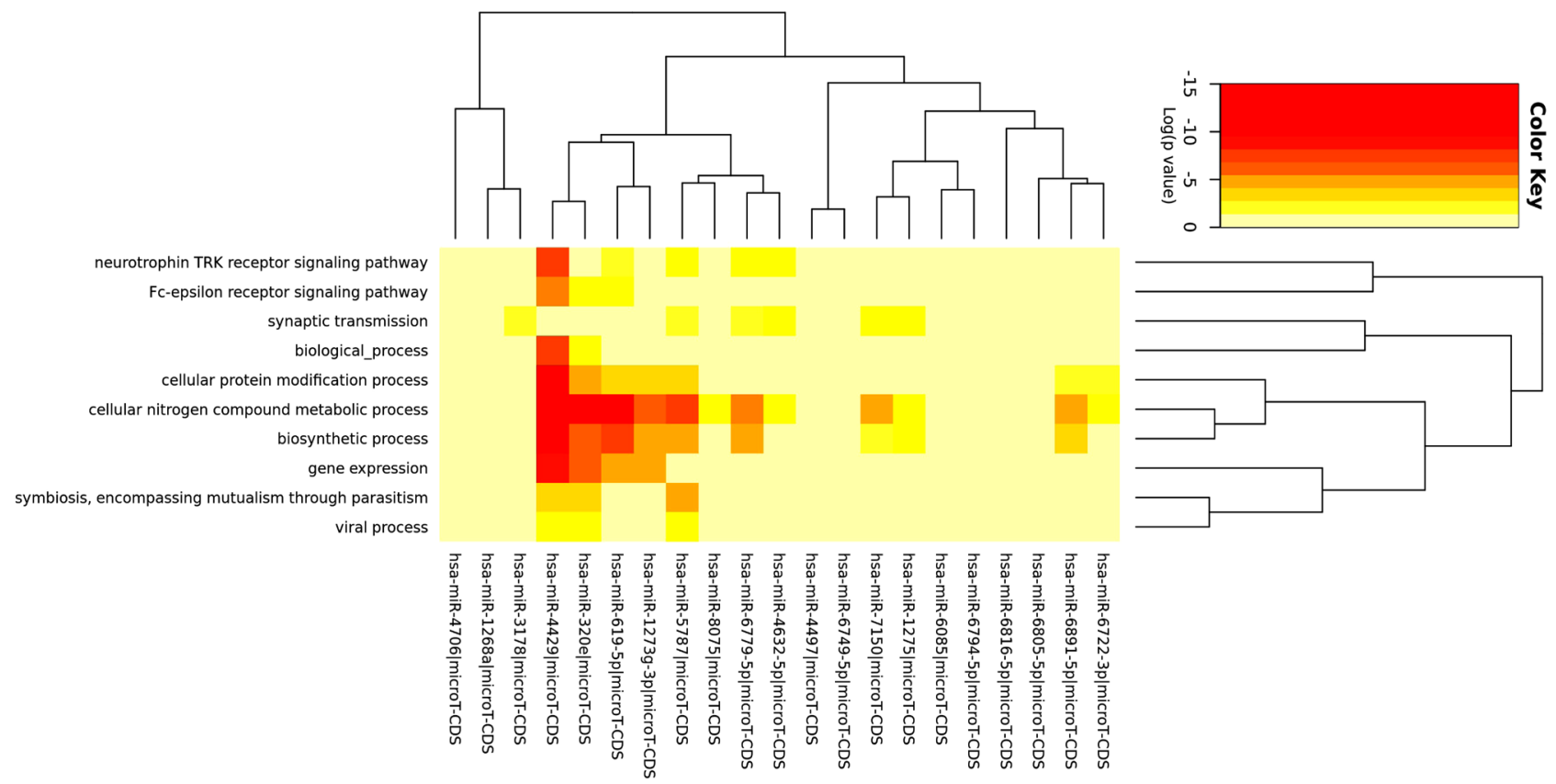

Figure 2

Heatmap of the enriched pathways related to the predicted miRNA targets of the up-regulated miRNA in PWS. The colour scale encodes the amount of $P$-value in logarithmic scale. The enrichment analysis was performed by using the Fisher's exact test with a Hypergeometric distribution corrected for multiple testing by using the False Discovery Rate (FDR) correction.

miR-106a-5p, miR-106b-5p and miR-93-5p in PWS could be related to important differences in adipogenesis and/or lipid metabolism and storage. This is also evident when comparing the PWS vs OB without steatosis in which the circulating levels of miR-122 were dramatically higher in OB compared to PWS ( $\mathrm{FC}=50.02 P<0.01)$. Mir-122 is a fundamental regulator of hepatic cholesterol and fattyacid metabolism (30), its downregulation alters the lipid metabolism in the liver $(44,45)$. Our observation, again, evidenced the different metabolic behaviour of the PWS compared to $\mathrm{OB}$, especially in consideration that serum miR-122 have been already associated to an altered lipid profile (46). Although a distinctive circulating miRNA signature characterizes PWS subject, unfortunately only few information exists about the function of the upregulated miRNA in this syndrome. The observed differences involve some miRNA regulating adipogenesis. Mir-4429 is actively released by the adipose tissue, working as inhibitor of ACVR2B in the TGFB signalling pathways, resulting in a pro-adipogenic condition in recipient cells (47). Mir-1275 usually has a lower expression in obese subjects, compared to normal people (48), it is responsible of pre-adipocyte differentiation by targeting the transcription factor ELK1 in VAT of overweight and obese subjects (48). Since the role of the adipose tissue in the active release of exosomal miRNAs, we might explain the observed differences in the circulating expression levels of miR-1275 and miR4429 by the different VAS/SAT $(\mathrm{V} / \mathrm{S})$ ratio and activity in the two analysed populations (9). Indeed, a distinct regulation of fat metabolism could be present in PWS. Despite the severe obesity, PWS adults have a more favourable insulin profile, associated with a different fat distribution $(9,49)$. The treatment with growth hormone $(\mathrm{GH})$ influences the VAS/SAT (V/S) ratio with a prevalence of subcutaneous fat accumulation (50). However, more translational studies are requested to clarify the association of between mir-1275, miR-4429 and the different fat distribution in a better way.

Taking together these observations, we hypothesise that the differences in miRNA profile between PWS and OB might origin from the different metabolic pathways involved in the genetic-derived obesity vs essential obesity. Indeed, differences in the metabolic profiles have already been observed $(8,51)$.

These differences in adipogenesis, lipid metabolism and storage, energy expenditure could derive from a differential pathway regulation between PWS and OB. Such dissimilarities are evidenced in the ontological analysis where, apart the general metabolic processes, in OB are present enriched cellular 'lipid metabolism pathways', 'FGF receptor signalling pathway', 'TGFBr signalling pathway', 'insulin receptor signalling pathways', with a https://ec.bioscientifica.com https://doi.org/10.1530/EC-18-0329 (c) 2018 The authors Published by Bioscientifica Ltd
This work is licensed under a Creative Commons Attribution-NonCommercial-NoDerivatives 4.0 International License. 
well-established role in obesity. On the contrary, none of the mentioned pathways was enriched in PWS. The poor enrichment obtained by the mir-predicted targets highlights the absence of information in terms of miRNA characterization. This is particularly important especially in consideration of the rare disease studied. Nevertheless, the interesting enrichment in the 'neurotrophin TRK receptor signalling' pathway pointed out the role of brainneurotrophic factors, such as BDNF.

BDNF is believed to function downstream of leptinmelanocortin signalling and to play an important role in regulating energy homeostasis and hyperphagia. Decreased levels of BDNF are associated to PWS and the study of Bochukova et al. (52) evidenced the downregulation of neurogenesis, neurotransmitter release, synaptic function and BDNF pathways in the hypothalamic transcriptome profile of PWS compared to normal subjects. Thus, some of the circulating miRNAs in PWS could mirror those alterations in the neurological pathways regulating food intake, energy balance and brain development.

To our knowledge, this is the first study comparing the circulating profile of a rare genetic obesity syndrome to essential (non-syndromic) obesity. Revealing the alteration in the expression of circulating small non-coding RNAs, such as miRNAs, could further contribute to identification of the different key regulatory cell pathways involved in the disease. This is particularly true when considering the emerging role of circulating miRNAs as 'messengers' in a sort of endocrine cell-to-cell communication. Our findings indicate the presence of a distinctive circulating miRNA profile between PWS and OB. The difference might derive from a differential regulation of cellular pathways, such as adipogenesis, lipid metabolism and accumulation, fat distribution and neurotrophic factor regulation. The identification of specific miRNA profile in PWS may represent an additional and valuable contribute in the clinical evaluation of hepatic impairment in these patients.

Although the rarity of PWS hampers the recruitment of wider study groups useful to draw definitive conclusions, we believe that this study performed on a small group of patients opens anyway new perspectives on molecular pathogenesis of syndromic (and non-syndromic) obesity. In addition, further validation studies should be conducted to confirm our preliminary observations in larger cohorts, mandatory to clarify the potential role of the cited miRNAs as possible circulating biomarkers to be used in clinics.

\section{Supplementary data}

This is linked to the online version of the paper at https://doi.org/10.1530/ ECC-18-0329.

\section{Declaration of interest}

The authors declare that there is no conflict of interest that could be perceived as prejudicing the impartiality of the research reported.

\section{Funding}

This work was partially supported by Progetti di Ricerca corrente, Istituto Auxologico Italiano, IRCCS, Milan, Italy ( research project code 01C628, acronym: NAFLDmiRNAPWS) and by an internal grant from the Italian Liver Foundation - ONLUS, Trieste, Italy.

\section{Author contribution statement}

A Sartorio, D Pascut and C Tiribelli designed the study. S Tamini and G Grugni enrolled the subjects and elaborated the database. A Minocci performed the abdominal echography. S Bresolin and G Basso performed the gene array. D Pascut, S Tamini did the analysis of the circulating miRNome. D Pascut and P Giraudi performed in silico miRNA target identification and GO enrichment analysis. D Pascut analysed the data and, together with A Sartorio and C Tiribelli, wrote the manuscript. G Grugni contributed to data interpretation and discussion writing. All authors contributed to the manuscript revision.

\section{Acknowledgements}

The authors are indebted with the patients and/or their parents for joining the study and they wish to acknowledge Dr Stefania Mai and Dr Alessandra De Col for their skilful collaboration in the recruitment of patients and first steps of laboratory management and Dr Giorgio Bedogni for his precious suggestions. We also thank Fondazione Cariparo and Associazione Italiana sulla Ricerca sul Cancro (G B and S B).

\section{References}

1 Nicholls RD, Knoll JH, Butler MG, Karam S \& Lalande M. Genetic imprinting suggested by maternal heterodisomy in nondeletion Prader-Willi syndrome. Nature 1989342 281-285. (https://doi. org/10.1038/342281a0)

2 Angulo MA, Butler MG \& Cataletto ME. Prader-Willi syndrome: a review of clinical, genetic, and endocrine findings. Journal of Endocrinological Investigation 201538 1249-1263. (https://doi. org/10.1007/s40618-015-0312-9)

3 Lionti T, Reid SM, White SM \& Rowell MM. A population-based profile of 160 Australians with Prader-Willi syndrome: trends in diagnosis, birth prevalence and birth characteristics. American Journal of Medical Genetics. Part A 2015 167A 371-378. (https://doi. org/10.1002/ajmg.a.36845)

4 Cassidy SB, Schwartz S, Miller JL \& Driscoll DJ. Prader-Willi syndrome. Genetics in Medicine 201214 10-26. (https://doi. org/10.1038/gim.0b013e31822bead0)

5 Kim JH \& Choi J-H. Pathophysiology and clinical characteristics of hypothalamic obesity in children and adolescents. Annals of Pediatric Endocrinology and Metabolism 201318 161-167. (https://doi. org/10.6065/apem.2013.18.4.161)

6 Theodoro MF, Talebizadeh Z \& Butler MG. Body composition and fatness patterns in Prader-Willi syndrome: comparison with simple obesity. Obesity 200614 1685-1690. (https://doi.org/10.1038/ oby.2006.193)

7 Lafortuna CL, Minocci A, Capodaglio P, Gondoni LA, Sartorio A, Vismara L, Rizzo G \& Grugni G. Skeletal muscle characteristics and motor performance after 2-year growth hormone treatment in adults with Prader-Willi syndrome. Journal of Clinical Endocrinology and

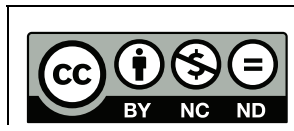

This work is licensed under a Creative Commons Attribution-NonCommercial-NoDerivatives 4.0 International License. 
Metabolism 201499 1816-1824. (https://doi.org/10.1210/jc.20133607)

8 Goldstone AP, Thomas EL, Brynes AE, Bell JD, Frost G, Saeed N, Hajnal JV, Howard JK, Holland A, Bloom SR. Visceral adipose tissue and metabolic complications of obesity are reduced in Prader-Willi syndrome female adults: evidence for novel influences on body fat distribution. Journal of Clinical Endocrinology and Metabolism 200186 4330-4338. (https://doi.org/10.1210/jcem.86.9.7814)

9 Talebizadeh Z \& Butler MG. Insulin resistance and obesity-related factors in Prader-Willi syndrome: comparison with obese subjects. Clinical Genetics 200567 230-239. (https://doi.org/10.1111/j.13990004.2004.00392.x)

10 Fintini D, Grugni G, Bocchini S, Brufani C, Di Candia S, Corrias A, Delvecchio M, Salvatoni A, Ragusa L, Greggio N, et al. Disorders of glucose metabolism in Prader-Willi syndrome: results of a multicenter Italian cohort study. Nutrition, Metabolism, and Cardiovascular Diseases 201626 842-847. (https://doi.org/10.1016/j. numecd.2016.05.010)

11 Grugni G, Crinò A, Bedogni G, Cappa M, Sartorio A, Corrias A, Di Candia S, Gargantini L, Iughetti L, Pagano C, et al. Metabolic syndrome in adult patients with Prader-Willi syndrome. Nutrition, Metabolism, and Cardiovascular Diseases 201323 1134-1140. (https:// doi.org/10.1016/j.numecd.2012.11.006)

12 Fintini D, Inzaghi E, Colajacomo M, Bocchini S, Grugni G, Brufani C, Cappa M, Nobili V, Cianfarani S \& Crinò A. Non-Alcoholic Fatty Liver Disease (NAFLD) in children and adolescents with Prader-Willi Syndrome (PWS). Pediatric Obesity 201611 235-238. (https://doi. org/10.1111/ijpo.12052)

13 Bedogni G, Grugni G, Nobili V, Agosti F, Saezza A \& Sartorio A. Is non-alcoholic fatty liver disease less frequent among women with Prader-Willi syndrome? Obesity Facts 20147 71-76. (https://doi. org/10.1159/000358570)

14 Desgagné V, Bouchard L \& Guérin R. microRNAs in lipoprotein and lipid metabolism: from biological function to clinical application. Clinical Chemistry and Laboratory Medicine 201755 667-686. (https:// doi.org/10.1515/cclm-2016-0575)

15 Shi C, Huang F, Gu X, Zhang M, Wen J, Wang X, You L, Cui X, Ji C $\&$ Guo X. Adipogenic miRNA and meta-signature miRNAs involved in human adipocyte differentiation and obesity. Oncotarget 20167 40830-40845. (https://doi.org/10.18632/oncotarget.13903)

16 Hartig SM, Hamilton MP, Bader DA \& McGuire SE. The miRNA interactome in metabolic homeostasis. Trends in Endocrinology and Metabolism 201526 733-745. (https://doi.org/10.1016/j. tem.2015.09.006)

17 Harboe M. A method for determination of hemoglobin in plasma by near-ultraviolet spectrophotometry. Scandinavian Journal of Clinical and Laboratory Investigation 195911 66-70. (https://doi. org/10.3109/00365515909060410)

18 Noe DA, Weedn V \& Bell WR. Direct spectrophotometry of serum hemoglobin: an Allen correction compared with a three-wavelength polychromatic analysis. Clinical Chemistry 198430 627-30.

19 Reczko M, Maragkakis M, Alexiou P, Grosse I \& Hatzigeorgiou AG. Functional microRNA targets in protein coding sequences. Bioinformatics 201228 771-776. (https://doi.org/10.1093/ bioinformatics/bts043)

20 Vlachos IS, Zagganas K, Paraskevopoulou MD, Georgakilas G, Karagkouni D, Vergoulis T, Dalamagas T \& Hatzigeorgiou AG. DIANA-miRPath v3.0: deciphering microRNA function with experimental support. Nucleic Acids Research 201543 W460-W466. (https://doi.org/10.1093/nar/gkv403)

21 Chou C-H, Chang N-W, Shrestha S, Hsu S-D, Lin Y-L, Lee W-H, Yang C-D, Hong H-C, Wei T-Y, Tu S-J, et al. miRTarBase 2016: updates to the experimentally validated miRNA-target interactions database. Nucleic Acids Research 201644 D239-D247. (https://doi.org/10.1093/ nar/gkv1258)
22 Kozomara A \& Griffiths-Jones S. miRBase: annotating high confidence microRNAs using deep sequencing data. Nucleic Acids Research 201442 D68-D73. (https://doi.org/10.1093/nar/gkt1181)

23 Liu WM, Mei R, Di X, Ryder TB, Hubbell E, Dee S, Webster TA, Harrington CA, Ho MH, Baid J, et al. Analysis of high density expression microarrays with signed-rank call algorithms. Bioinformatics 200218 1593-1599. (https://doi.org/10.1093/ bioinformatics/18.12.1593)

24 Karbiener M, Pisani DF, Frontini A, Oberreiter LM, Lang E, Vegiopoulos A, Mössenböck K, Bernhardt GA, Mayr T, Hildner F, et al. MicroRNA-26 family is required for human adipogenesis and drives characteristics of brown adipocytes. Stem Cells 201432 1578-1590. (https://doi.org/10.1002/stem.1603)

25 Ying W, Tseng A, Chang RC-A, Wang H, Lin Y-L, Kanameni S, Brehm T, Morin A, Jones B, Splawn T, et al. miR-150 regulates obesity-associated insulin resistance by controlling B cell functions. Scientific Reports 20166 20176. (https://doi.org/10.1038/srep20176)

26 Lozano-Bartolomé J, Llauradó G, Otin MP, Altuna-Coy A, RojoMartínez G, Vendrell J, Jorba R, Rodríguez-Gallego E \& Chacón MR. Altered expression of miR-181a-5p and miR-23a-3p is associated with obesity and TNF $\alpha$-induced insulin resistance. Journal of Clinical Endocrinology and Metabolism 2018103 1447-1458. (https://doi. org/10.1210/jc.2017-01909)

27 Deiuliis JA, Syed R, Duggineni D, Rutsky J, Rengasamy P, Zhang J, Huang K, Needleman B, Mikami D, Perry K, et al. Visceral adipose microRNA 223 is upregulated in human and murine obesity and modulates the inflammatory phenotype of macrophages. PLOS ONE 201611 e0165962. (https://doi.org/10.1371/journal.pone.0165962)

28 Zaiou M, El Amri H \& Bakillah A. The clinical potential of adipogenesis and obesity-related microRNAs. Nutrition, Metabolism, and Cardiovascular Diseases 201828 91-111. (https://doi. org/10.1016/j.numecd.2017.10.015)

29 Chen Y, Buyel JJ, Hanssen MJW, Siegel F, Pan R, Naumann J, Schell M, van der Lans A, Schlein C, Froehlich H, et al. Exosomal microRNA miR-92a concentration in serum reflects human brown fat activity. Nature Communications 20167 11420. (https://doi. org/10.1038/ncomms11420)

30 Esau C, Davis S, Murray SF, Yu XX, Pandey SK, Pear M, Watts L, Booten SL, Graham M, McKay R, et al. miR-122 regulation of lipid metabolism revealed by in vivo antisense targeting. Cell Metabolism 20063 87-98. (https://doi.org/10.1016/j.cmet.2006.01.005)

31 Wang R, Hong J, Cao Y, Shi J, Gu W, Ning G, Zhang Y \& Wang W. Elevated circulating microRNA-122 is associated with obesity and insulin resistance in young adults. European Journal of Endocrinology 2015172 291-300. (https://doi.org/10.1530/EJE-14-0867)

32 Yamada H, Suzuki K, Ichino N, Ando Y, Sawada A, Osakabe K, Sugimoto K, Ohashi K, Teradaira R, Inoue T, et al. Associations between circulating microRNAs (miR-21, miR-34a, miR-122 and miR451) and non-alcoholic fatty liver. Clinica Chimica Acta 2013424 99-103. (https://doi.org/10.1016/j.cca.2013.05.021)

33 Chamberlain SJ. RNAs of the human chromosome 15q11-q13 imprinted region. Wiley Interdisciplinary Reviews. RNA 20134 155-166. (https://doi.org/10.1002/wrna.1150)

34 Arner P \& Kulyté A. MicroRNA regulatory networks in human adipose tissue and obesity. Nature Reviews. Endocrinology 201511 276-288. (https://doi.org/10.1038/nrendo.2015.25)

35 Kuryłowicz A, Wicik Z, Owczarz M, Jonas MI, Kotlarek M, Świerniak M, Lisik W, Jonas M, Noszczyk B \& PuzianowskaKuźnicka M. NGS reveals molecular pathways affected by obesity and weight loss-related changes in miRNA levels in adipose tissue. International Journal of Molecular Sciences 201719 66-80. (https://doi. org/10.3390/ijms19010066)

36 Thomou T, Mori MA, Dreyfuss JM, Konishi M, Sakaguchi M, Wolfrum C, Rao TN, Winnay JN, Garcia-Martin R, Grinspoon SK, et al. Adipose-derived circulating miRNAs regulate gene expression
This work is licensed under a Creative Commons Attribution-NonCommercial-NoDerivatives 4.0 International License. 
in other tissues. Nature 2017542 450-455. (https://doi.org/10.1038/ nature21365)

$37 \mathrm{Ng} \mathrm{R}$, Wu H, Xiao H, Chen X, Willenbring H, Steer CJ \& Song G. Inhibition of microRNA-24 expression in liver prevents hepatic lipid accumulation and hyperlipidemia. Hepatology $201460554-564$. (https://doi.org/10.1002/hep.27153)

38 Iliopoulos D, Drosatos K, Hiyama Y, Goldberg IJ \& Zannis VI. MicroRNA-370 controls the expression of microRNA-122 and Cpt1alpha and affects lipid metabolism. Journal of Lipid Research 2010 51 1513-1523. (https://doi.org/10.1194/jlr.M004812)

39 Nunez Lopez YO, Garufi G \& Seyhan AA. Altered levels of circulating cytokines and microRNAs in lean and obese individuals with prediabetes and type 2 diabetes. Molecular BioSystems 201613 106-121. (https://doi.org/10.1039/C6MB00596A)

40 Li H, Li T, Wang S, Wei J, Fan J, Li J, Han Q, Liao L, Shao C \& Zhao RC. miR-17-5p and miR-106a are involved in the balance between osteogenic and adipogenic differentiation of adiposederived mesenchymal stem cells. Stem Cell Research 201310 313-324. (https://doi.org/10.1016/j.scr.2012.11.007)

41 Wu Y, Zuo J, Zhang Y, Xie Y, Hu F, Chen L, Liu B \& Liu F. Identification of miR-106b-93 as a negative regulator of brown adipocyte differentiation. Biochemical and Biophysical Research Communications 2013438 575-580. (https://doi.org/10.1016/j. bbrc.2013.08.016)

42 Cioffi M, Vallespinos-Serrano M, Trabulo SM, Fernandez-Marcos PJ, Firment AN, Vazquez BN, Vieira CR, Mulero F, Camara JA, Cronin UP, et al. MiR-93 controls adiposity via inhibition of Sirt7 and Tbx3. Cell Reports 201512 1594-1605. (https://doi.org/10.1016/j. celrep.2015.08.006)

43 Kennedy L, Bittel DC, Kibiryeva N, Kalra SP, Torto R \& Butler MG. Circulating adiponectin levels, body composition and obesity-related variables in Prader-Willi syndrome: comparison with obese subjects. International Journal of Obesity 200630 382-387. (https://doi. org/10.1038/sj.ijo.0803115)

44 Cheung O, Puri P, Eicken C, Contos MJ, Mirshahi F, Maher JW, Kellum JM, Min H, Luketic VA \& Sanyal AJ. Non-alcoholic steatohepatitis is associated with altered hepatic microRNA expression. Hepatology 200848 1810-1820. (https://doi.org/10.1002/ hep.22569)
45 Hsu SH, Wang B, Kota J, Yu J, Costinean S, Kutay H, Yu L, Bai S, Perle KL, Chivukula RR, et al. Essential metabolic, anti-inflammatory, and anti-tumorigenic functions of miR-122 in liver. Journal of Clinical Investigation 2012122 2871-2883. (https://doi.org/10.1172/ JCI63539)

46 Willeit P, Skroblin P, Moschen AR, Yin X, Kaudewitz D, Zampetaki A, Barwari T, Whitehead M, Ramírez CM, Goedeke L, et al. Circulating microRNA-122 is associated with the risk of new-onset metabolic syndrome and type 2 diabetes. Diabetes 201766 347-357. (https:// doi.org/10.2337/db16-0731)

47 Ferrante SC, Nadler EP, Pillai DK, Hubal MJ, Wang Z, Wang JM, Gordish-Dressman H, Koeck E, Sevilla S, Wiles AA, et al. Adipocytederived exosomal miRNAs: a novel mechanism for obesity-related disease. Pediatric Research 201577 447-454. (https://doi.org/10.1038/ pr.2014.202)

48 Pang L, You L, Ji C, Shi C, Chen L, Yang L, Huang F, Zhou Y, Zhang J, Chen X, et al. miR-1275 inhibits adipogenesis via ELK1 and its expression decreases in obese subjects. Journal of Molecular Endocrinology 201657 33-43. (https://doi.org/10.1530/JME-16-0007)

49 Lacroix D, Moutel S, Coupaye M, Huvenne H, Faucher P, Pelloux V, Rouault C, Bastard JP, Cagnard N, Dubern B, et al. Metabolic and adipose tissue signatures in adults with Prader-Willi syndrome: a model of extreme adiposity. Journal of Clinical Endocrinology and Metabolism 2015100 850-859. (https://doi.org/10.1210/jc.2014-3127)

50 Tanaka Y, Abe Y, Oto Y, Itabashi H, Shiraishi M, Yoshino A, Obata K, Murakami N \& Nagai T. Characterization of fat distribution in Prader-Willi syndrome: relationships with adipocytokines and influence of growth hormone treatment. American Journal of Medical Genetics. Part A 2013 161A 27-33. (https://doi.org/10.1002/ ajmg.a.35653)

51 Hirsch HJ, Gross I, Pollak Y, Eldar-Geva T, Gross-Tsur V. Irisin and the metabolic phenotype of adults with Prader-Willi syndrome. PLOS ONE 201510 e0136864. (https://doi.org/10.1371/journal. pone.0136864)

52 Bochukova EG, Lawler K, Croizier S, Keogh JM, Patel N, Strohbehn G, Lo KK, Humphrey J, Hokken-Koelega A, Damen L, et al. A transcriptomic signature of the hypothalamic response to fasting and BDNF deficiency in Prader-Willi syndrome. Cell Reports 201822 3401-3408. (https://doi.org/10.1016/j.celrep.2018.03.018)

Received in final form 1 October 2018

Accepted 8 October 2018

Accepted Preprint published online 9 October 2018
This work is licensed under a Creative Commons Attribution-NonCommercial-NoDerivatives 4.0 International License. 